\title{
Usability and User Satisfaction of Segmented Animation Courseware with Linear Program-Controlled Feature
}

\author{
Anuar Hassan and Ahmad Zamzuri Mohamad Ali
}

\begin{abstract}
The purpose of this study is to determine the usability and user satisfaction of the Segmented Animation Courseware Featured with Linear Program-Controlled approach. The courseware on the OSI Model topic was developed based on theories, principles and literature overview conducted. The DDD-E model has been utilized as an instructional design reference throughout the development process, which consists of four phases of activity namely Decide, Design, Develop and Evaluate. Usability and user satisfaction test is conducted to gain input on aspects of teaching and learning, motivation, design and technical features. This instrument consists of 15 evaluation items that need to be answered by students. The study sample consisted of 35 Diploma in Electrical Engineering final semester, students from the Sultan Salahuddin Abdul Aziz Shah Polytechnic. The Data obtained was analyzed using the mean descriptive method. Findings from the usability and user satisfaction test indicated that the courseware had adhered to the development standards and is suitable to be used as a teaching medium for the OSI Model topic.
\end{abstract}

Index Terms-Animation, courseware, instructional, segmentation, program-controlled.

\section{INTRODUCTION}

Malaysia is moving towards an evolution in education by ascribing to Computer Aided Learning (CAL), in which the computer appears to be the alternative technology in aiding learning [1]-[3]. Basically, the CAL mode has actually created a new paradigm in the current instructional technology field.

In the context of the design and development of CAL specifically the courseware, the need of special and careful attention, including precise and meticulous planning before, during and after the development process is important in ensuring the quality. Generally, when designing learning software, a designer needs to follow a few guided steps. This is because all the necessary guidance needs to be considered during the process of designing and developing the courseware. Guidance is important in order to avoid being way leaded or lost during the development process [4]-[6].

Instructional design guidance or model has long existed since the 1940s and it is becoming increasingly relevant in this decade, especially in the education field [7]. The instructional design model is a combination of procedure used to create an effective product in order to achieve the learning objectives that have been formulated [8]-[10].

Manuscript received November 17, 2014; revised March 13, 2015

The authors are with the Faculty of Art, Computing and Creative Industry, Universiti Pendidikan Sultan Idris, Malaysia (e-mail: anuar5225@gmail.com).
This argument is in line with [11], [12] which stated that a good courseware design would be able to contribute towards an encouraging learning outcome. Hence, in ensuring that the courseware design is accurate and suitable, the adequate instructional design model should be identified before the development process begins.

In relation to that, this study utilizes the DDD-E multimedia design and development model. "Reference [13] also stated that the DDD-E model is capable of guiding the multimedia development process that is relevant to the technology changes of today."

\section{Research Methodology}

The main objective of this study is to determine the usability aspect of a courseware with segmented animation in a program-controlled mode. The DDD-E model has been adopted as the guidelines for the whole courseware development. Each phase of development starting Decide, Design, Develop and Evaluate has its own contribution towards the main objective of the research. A field of study with the survey research approach was carried out on randomly selected students, whereby a group of 35 Diploma in Electrical Engineering final year students was exposed to this courseware. The assessment instrument was adapted from Jamalludin, Baharudin \& Zaidatun [14]. It contained 15 items that were divided into four dimensions, which were teaching and learning, motivation, design and technical aspects. The 5-point Likert scale with a range of 1, representing "totally disagree" to 5 , representing "totally agree" had been used in this instrument. The survey was conducted after 30 minutes students explored the courseware. Detail of the research framework of this study is divided into two stages as shown in Table I.

TABLE I: RESEARCH FRAMEWORK

\begin{tabular}{|c|c|}
\hline Phase & Description \\
\hline I & $\begin{array}{r}\text { Development using DDD-E Model (Decide- } \\
\text { Design-Develop-Evaluate) }\end{array}$ \\
\hline II & Testing \& Evaluation \\
\hline
\end{tabular}

1) Development Process - Karen and Ann had developed the DDD-E in 1998.The justification for choosing this model is because of its characteristics that encompass the basic development phases such as analysis, design, development and implementation. Whereas, continuous evaluation allows courseware developed could be evaluated and improved throughout the process. Besides, the fortes of the other models are as stated earlier in this study [15]-[17].

2) Testing and Evaluation - The testing and evaluation 
phase uses the actual learning condition. This phase is initiated after the courseware development process is completed.

\section{DEVELOPMENT PHASE}

The designing, developing and testing of the courseware process was mainly grounded on DDD-E Instructional Design (ID) framework, which comprises of Decide, Design, Develop and Evaluate phases.

\section{A. Decide}

The Networking System Module was chosen for developing the prototype. This module is the core module of Diploma in Networking Systems. The topic Troubleshooting the Networks was single outed for the prototype development. Several factors were considered in deciding the specific topic. A part of the factors are the abstract nature of the contents; especially explanations of the Open System Connection (OSI) model operations.

Several studies have revealed that OSI topic needs to be mastered before mastering the troubleshooting activities. The task of every layer of OSI is important to be understood clearly. Furthermore, troubleshooting the network process comprises seven aspects emphasized in the OSI model. Most of the lecturers who teach this module are not capable of providing precise illustrations regarding the association between troubleshooting and the OSI model, and this causes the students to become burdened, and confused [18]-[20].

\section{B. Design}

The intermediary medium between the consumer and computer systems is through the courseware interface display. The definition of a courseware interface is a series of graphic displays on the computer in order to convey information to the user [21], [22]. Therefore, the courseware interface designing process needs special attention to ensure the effectiveness in the teaching and learning process.

One of the most significant current discussions in the courseware interface design is the combination of elements such as texts, graphics, animation, videos and the animation. The relationship between these elements on the interface is known as the layout. According to [23], a good layout would help the information in the interface conveyed in a supportive manner and create a suitable interactive relationship between the user and the computer. This would help in maintaining the concentration of the courseware user during the learning sessions [24].

"Reference [4] provide in depth analysis of the principle of multimedia interface in context of dividing the interface into blocks such as animation blocks, text blocks and so forth, as shown in Fig. 1". The process to layout and arrange the block of texts, navigation and animation in the interface needs to be lucid and not complicated. Thus, separation of the title block, animation block, control button block and the number of display blocks must be customized for each section of the interface. This would render a well-arranged layout of blocks on the interface. The layout factor also needs to be consistent on every other interface display. On the other hand, the type of texts also will play important role in designing multimedia.
A text is defined as a reference to the arrangement of alphabets that referred to several combinations of symbols such as alphabets, numbers, different fonts, font styles and punctuations. In relation to the text, the concept of texts that are simple and concise needs to be ascribed to when designing multimedia. The justification for texts that are brief and concise is preferably less than half the size of the screen used. Bold fonts can be used to emphasize an idea of a concept, but it should avoid making the text look like a link or a hypertext.

Hence, when developing the Courseware prototype for this study, texts in Arial (San Serif) form would be used for the whole software except on certain sections that would need different visual effects. This type of texts is suitable for displays on computer screens because it is easy and fast to read.

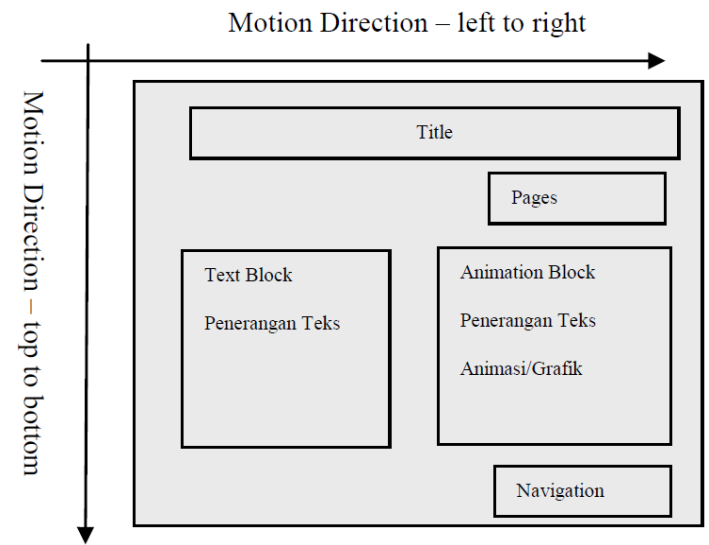

Fig. 1. Interface design principle [5].

\section{Develop}

A suitable approach of presentation strategy is capable of increasing the effectiveness of the prototype. The multimedia presentation strategies usually imposed in courseware presentation are drills, simulations, inquiries, tutorials, instructional games and case studies. Hence, the courseware designer these days, usually combine more than one strategy in developing their product. Therefore, choosing a suitable presentation strategy is important in achieving the objectives of teaching. According to [25], nine learning activities can be used as a guide when choosing strategies for courseware development, as shown in Table II.

TABLE II : MULTIMEDIA LEARNING STRATEGY [24]

\begin{tabular}{|l|l|l|l|l|l|l|l|l|l|}
\hline Strategy & \multicolumn{7}{|c|}{ Learning Event } \\
\hline & 1 & 2 & 3 & 4 & 5 & 6 & 7 & 8 & 9 \\
\hline Intensive & $\mathrm{X}$ & & & & & $\mathrm{X}$ & $\mathrm{X}$ & & \\
\hline Tutorial & $\mathrm{X}$ & $\mathrm{X}$ & $\mathrm{X}$ & $\mathrm{X}$ & $\mathrm{X}$ & $\mathrm{X}$ & $\mathrm{X}$ & $\mathrm{X}$ & $\mathrm{X}$ \\
\hline Inquiries & & & & $\mathrm{X}$ & $\mathrm{X}$ & $\mathrm{X}$ & $\mathrm{X}$ & & \\
\hline Simulation & & $\mathrm{X}$ & & $\mathrm{X}$ & & $\mathrm{X}$ & $\mathrm{X}$ & & \\
\hline Socratic & & & & $\mathrm{X}$ & $\mathrm{X}$ & $\mathrm{X}$ & $\mathrm{X}$ & & \\
\hline Case Study & & & & $\mathrm{X}$ & & $\mathrm{X}$ & $\mathrm{X}$ & & \\
\hline Games & $\mathrm{X}$ & & $\mathrm{X}$ & & $\mathrm{X}$ & $\mathrm{X}$ & & \\
\hline Learning Event & & & & \\
1. Gaining Attention \\
2. Informing learners about the objective \\
3. Stimulating recall of Prior Learning \\
4. Presenting the stimulus \\
5. Providing learning guidance \\
6. Eliciting Performance \\
7. Providing Feedback \\
8. Assessing Performance \\
9. Enhancing Retention and transfer \\
\hline
\end{tabular}


In this study, the tutorial presentation strategy was used for developing the prototype. This strategy is capable of giving a concise understanding about teaching abstract topics. This strategy lays more importance on subject content presentation. With this approach imposed on the presentation strategy, the teaching methodology is similar to classroom teaching whereby it begins with a presentation of the contents followed by a series of reinforcements and ends with the assessment process [22].

The graphic components in multimedia development consist of the screen display's background, the interface of each display, the montage, graphs, pictures, buttons and icons The combination of all these elements in the courseware is capable of producing a multimedia set that is complete and of quality [5], [25], [26], [14]. In this study, simple graphic components and segmented animation which is capable of stimulating the student's memory to further explore the contents of software was imposed [27], [28]. This is due to the adequate activation of the scheme that occurs during the learning process [29], [30]. Besides that, the effect of the graphics together with the audio on the montage is capable of stimulating the student's interest to further explore the courseware [27], [28]. Therefore, animation is seen as being capable of reducing the student's cognitive load when following the learning and teaching sessions.

Meanwhile, in the courseware main menu, there are several links to the main menu and among them are the Guide, Synopsis, Learning Outcome and Menu. The position of the links to the main menu, which is on the upper side of the courseware, would help students to interact more effectively when exploring the courseware contents [23]. Besides that, the layout technique also uses the layout principle [5]. An example of a complete courseware is shown in Fig. 2 and Fig. 3.

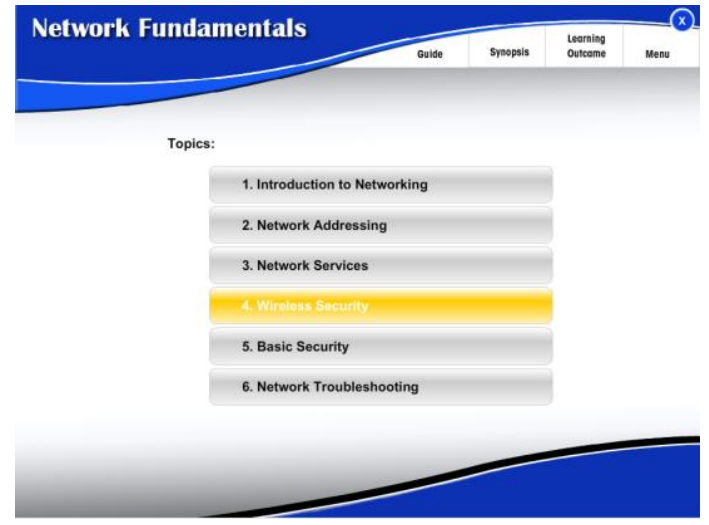

Fig. 2. Screen layout.

\section{0}

Fig. 3. Segmentation and navigation button

\section{Evaluate}

The analysis of the courseware was carried out through questionnaire feedback. The analysis was not only limited from the physical aspect but also covered the overall performance, especially the usability and user satisfaction when using the courseware as an instructional medium. In order to evaluate the usability and user satisfaction, the evaluation was conducted once the design and development process was fully completed.

\section{FINDING AND DISCUSSION}

The quantitative data collected through usability and user satisfaction test. The descriptive statistic was used to determine the mean values and the standard deviation for each item. The findings are as follows:

\section{A. The Teaching and Learning Dimension}

The students agreed that the learning process had become easier to understand, especially concerning abstract topics such as operations of the OSI Model $(M=4.5, S P=0.8)$, the basic technics involved in the maintenance of the computer networking system $(M=4.3, S P=0.9)$ and the peer-to-peer communication process $(M=4.6, S P=0.8)$. This is because the arrangements of the contents in animation form were clear and well structured $(M=4.4, S P=0.8)$.

\section{B. The Motivation Dimension}

This Courseware was capable of stimulating the student's interest to continue following the learning lessons although some topics were difficult. Based on the user tests, the students were happy to use this courseware $(M=4.5, S P=$ 0.8 ). Besides that, they also hope that other modules would also use the courseware approach $(M=4.3, S P=1.1)$. Indirectly, this courseware was capable of increasing the students' level of interest in this module $(M=4.2, S P=1.0)$ and to make this module as their choice $(M=4.2, S P=1.07)$.

\section{The Design Dimension}

It was found that the software that was developed has an attractive design and is capable of helping students understand the topic troubleshooting the network. A good color combination $(M=4.3, S P=0.9)$, legible writing $(M=$ 4.2, $S P=1.1)$, music during the montage $(M=4.1, S P=0.8)$, effective graphic animation movements $(M=4.2, S P=0.7)$ and suitable animation based on the contents of the module $(M=4.1, S P=1.1)$ was successful in producing an incisive learning courseware set.

\section{The Technical Aspect Dimension}

A complete and compatible courseware and the minimum computer specifications in the laboratory need to be coordinated. Therefore, the findings on consumerism has shown that the developed courseware has a good level of perfection $(M=3.9, S P=0.6)$. Meanwhile, the computer specifications in the polytechnic's computer laboratory had fulfilled the minimum standards $(M=4.3, S P=0.9)$.

Overall, it shows that the students agreed and satisfied with the usability of the courseware with segmented animation in linear program-controlled conditions to be used as a learning medium in Malaysian Polytechnics.

\section{CONCLUSION}

The finding provides evidence that the development of the courseware is seen as being very effective and has managed to attract the student's interest to further explore teaching 
contents concerning the OSI Model. This has been proved by several studies, which have shown that using dynamic animation is better compared to conventional learning. This courseware has elements such as the ease in teaching and learning through animation, aspects of motivation, a dynamic and interactive functional design and the priority towards technical aspects that enables it to be used on any computer with differing versions of operating systems. However, to ensure that students get to use this courseware with ease, the usability and student satisfaction test was carried out and the results of the analysis showed a positive effect from the student's perspective. This shows that the courseware has met the standards of instructional development, especially for the computer networking syllabus in Malaysian Polytechnics.

\section{REFERENCES}

[1] D. Dorothy, A. Norlidah, and S. Saedah, "Merekabentuk bagi pembelajaran atas dalam talian: Pedagogi Modul CmL," Jurnal Kurikulum \& Pengajaran Asia Pasifik, vol. 1, no. 2, pp. 5-9, January 2013.

[2] Kementerian Pelajaran Malaysia. (September 2012). Preliminary Report: Malaysia Education Blueprint 2013-2025. [Online]. Available: http://www.moe.gov.my/userfiles/file/PPP/Preliminary-Blueprint-Eng .pdf.

[3] J. Rozinah, Asas-Asas Multimedia Dalam Pendidikan, Kuala Lumpur: Utusan Publications \& Distributors Sdn Bhd, 2000, ch. 1, pp. 1-9.

[4] M. A. A. Zamzuri, W. Rahani, S. K. Anuar, and I. M. Zaffwan, "Reading on the computer screen: Does font type has effects on web text readability?" International Education Studies, vol. 6, no. 3, pp. 26-35, January 2013.

[5] M. A. A. Zamzuri, R. S. Norbaizura, and S. Syamsulaini, "Mengkaji jujukan tumpuan pelajar terhadap antaramuka koswer," in Proc. the 4th International Conference on Teacher Education: Join Conference UPI \& UPSI, Bandung, Indonesia, 2010, pp. 629-637.

[6] H. Jamalludin, A. Baharuddin, and T. Zaidatun, Siri 1: Macromedia Attain 5, Kuala Lumpur: Venton Publishing Sdn Bhd, 2000, pp. 14-44.

[7] R. A. Reiser and J. V. Dempsey, Trends and Issues in Instructional Design and Technology, $3^{\text {rd }}$ ed., Boston, MA: Pearson Education Inc., 2012, pp. 32-48.

[8] A. Baharuddin, S. R. Sumarni, and S. Manimegalai, Rekabentuk Perisian Multimedia, Johor Bharu: Universiti Teknologi Malaysia, 2002, pp. 65-79.

[9] N. M. Avouris, N. Tselios, and E. C. Tatakis, "Development and evaluation of a computer-based laboratory teaching tool," Computer Application in Engineering Education, vol. 9, no. 1, pp. 8-19, March 2001.

[10] M. Molenda, J. A. Pershing, and C. M. Reigeluth, "Designing instructional systems," in The ASTD Training and Development Handbook - A Guide to Human Resource Development, S. L. Craig, Ed., London: McGraw-Hill,1996, pp. 56-69.

[11] B. P. Beaudin and D. Quick. (June 1996). Instructional video evaluation instrument. Journal of Extension. [Online]. 34(3). Available: http://www.joe.org/joe/1996june/a1.php.

[12] M. Taylor, S. Duffy, and G. Hughes, "The use of animation in higher education teaching to support students with dyslexia," Education + Training, vol. 49, no. 1, pp. 25-35, June 2007.

[13] S. I. Karen and E. B. Ann, Multimedia Projects in Education: Designing, Producing and Assessing, $2^{\text {nd }}$ ed., Westport, CT: Libraries Unlimited, pp. 25-37, 2002.

[14] H. Jamalludin, A. Baharuddin, and T. Zaidatun, Pembangunan Perisian Multimedia: Satu Pendekatan Sistematik, Kuala Lumpur: Venton Publishing Sdn Bhd, pp. 5-68, 2001.

[15] S. I. Karen and E. B. Ann, Multimedia Projects in Education: Designing, Producing and Assessing, $3^{\text {rd }}$ Ed., Westport, CT: Libraries Unlimited, pp. 10-56, 2006.

[16] S. I. Karen and E. B. Ann, Multimedia Projects in Education: Designing, Producing and Assessing, Westport, CT: Libraries Unlimited, pp. 15-63, 1998.
[17] M. Holliday, "Animation of computer networking concepts," $A C M$ Journal of Educational Resources in Computing, vol. 3, no. 2, June 2003.

[18] G. Dowling, A. Tickle, K. Stark, J. Rowe, and M. Godat, "Animation of complex data communications concepts may not always yield improved learning outcomes," in Proc. the $7^{\text {th }}$ Australasian Conference on Computing Education, New Castle, Australia, 2005, pp. 151-154.

[19] C. Goldstein, S. Leistein, K. Stark, and A. Tickle, "Using a network simulation tool to engage students in active learning enhances their understanding of complex data communications concepts," in Proc. the $7^{\text {th }}$ Australasian Conference on Computing Education, New Castle, Australia, 2005, pp. 223-228.

[20] J. Preece, Y. Rogers, and H. Sharp, Interaction Design, New York, NY: John Wiley \& Sons, Inc., 2002, pp. 23-69.

[21] S. Alessi and S. Trollip, Computer-Based Instruction: Methods and Development, $2^{\text {nd }}$ ed., New Jersey, NJ: Prentice Hall, 1991, pp. 8-67.

[22] F. T. Hofstetter, Multimedia Literacy, $3^{\text {rd }}$ Ed., New York, NY: McGraw-Hill, 2001, pp. 35-69.

[23] G. U. Kulasekara, B. G. Jayatilleka, and U. Coomaraswamy, "Learner perceptions on instructional design of multimedia in learning abstract concepts in science at a distance," Open Learning Journal: The Journal of Open, Distance and e-Learning, vol. 26, no. 2, pp. 113-126, May 2011.

[24] R. M. Gagne, L. J. Briggs, and W. W. Wager, Principles of Instructional Design, $4^{\text {th }}$ ed., Fort Worth, TX: Harcourt Brace Jovanovich, 1992, pp. 19-47.

[25] M. A. A. Zamzuri, "Effective instructional courseware design to Improve students' cognitive skills: A practical guide for educators as multimedia author," in Proc. the 2nd International Malaysian Education Technology Convention, Kuantan, Pahang, 2008, pp. 245-252.

[26] H. Jamalludin and T. Zaidatun, Multimedia Menerusi Macromedia Flash MX 2004, Kuala Lumpur: Venton Publishing Sdn. Bhd, 2004, pp. 56-67.

[27] L. P. Rieber, S. C. Tzeng, and K. Tribble, "Discovery learning, representation, and explanation within a computer-based simulation Finding the right mix," Learning and Instruction, vol. 14, no. 3, pp. 307-323, June 2004.

[28] L. P. Rieber, "Animation in a computer based instruction," Educational Technology Research and Development, vol. 38, no. 1, pp. $77-86,1990$.

[29] R. K. Lowe and J. M. Boucheix, "Manipulable models for investigating processing of dynamic diagrams," in Diagrammatic Representation and Inference, A. K. Goel, M. Jamnik, and N. H. Narayanan, Eds., Berlin:Springer-Verlag, 2010, pp. 319-32.

[30] M. Hegarty, M. S. Canham, and S. I. Fabrikant, "Thinking about the weather: How display salience and knowledge affect performance in a graphic inference task," Journal of Experimental Psychology: Learning, Memory and Cognition, vol. 36, no. 1, pp. 37-53, January 2010.

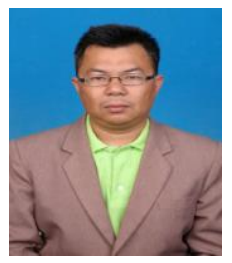

Anuar Hassan is currently a $\mathrm{PhD}$ student in the Faculty of Art, Computing and Creative Industry, Universiti Pendidikan Sultan Idris, Malaysia. He has a bachelor degree in mechanical engineering plant engineering and the master in education from Universiti Teknologi Malaysia. His research interest is instructional technology.

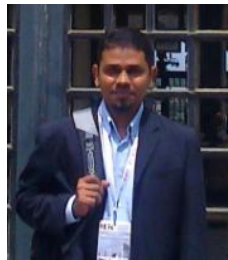

Ahmad Zamzuri Mohamad Ali is an associate professor of multimedia in the Faculty of Art, Computing and Creative Industry, Universiti Pendidikan Sultan Idris, Malaysia. He has a bachelor degree in electrical engineering from Universiti Teknologi Malaysia, a master in education from Universiti Teknologi Malaysia and a $\mathrm{PhD}$ in multimedia design from Universiti Sains Malaysia. $\mathrm{He}$ has taught both face-to-face and online classes in higher education for over 15 years. His research and publication interests are multimedia design, instructional technology, ICT in education and open source in education. 